\title{
Research on the Gratitude Education of Contemporary College Students from the Perspective of Positive Psychology
}

\author{
Wu Yue ${ }^{1, a}$, Zhai YuXiang ${ }^{2, b}$ \\ 1,2Xi'an University of Technology, Xi'an, Shaanxi,710048,China \\ awuyue@xaut.edu.cn \\ bzhaiyuxiang@xaut.edu.cn
}

Key words: positive psychology; college students; gratitude education; educational strategy

\begin{abstract}
Nowadays, the lack of gratitude education has become one of the most common phenomena in colleges and universities, which often leads to the fact that college students are not willing to and able to show gratitude to others. Ignorance of gratitude behavior will not only bring adverse effects on their personal growth but also affect their interpersonal relationships as well as the harmonious development of society. Therefore, positive psychology should be used to cultivate good psychological quality of college students, thus promoting the development of gratitude education.
\end{abstract}

\section{Introduction}

Throughout the social news reports in recent years, lack of gratitude education has become a common problem among contemporary college students, which not only has a negative impact on their personal development and interpersonal relationships, but also brings some threat to the establishment of harmonious campus and society. Therefore, the gratitude education has aroused wide attention. In this context, it is necessary to actively carry out gratitude education for contemporary college students and strengthen their sense of gratitude and psychological quality. The guidance through positive psychology makes them clear the significance of showing gratitude to others and help them set up correct awareness.

2. The psychological characteristics of college students from the perspective of positive psychology

\subsection{A strong sense of self-desire to know the world}

As college students age and the education improves, college students often show strong thinking ability, which also improves their own self-consciousness to a certain extent. In this context, contemporary college students tend to give full attention to their own changes as well as great interest and strong desire to the new things. As a result, they always show strong initiative for the social phenomenon.

\subsection{A strong sense of autonomy desire to live independently}

Before entering the college, college students are subject to parents and teachers in their study and daily life. After entering the university, they gradually develop a strong sense of autonomy and are eager to live independently and make their own decisions, thus improving themselves and achieving independent development.

\subsection{A strong sense of communication desire for interpersonal relationships}

As most of college students are the only child in their family, they do not have strong interpersonal skills due to the influence of previous learning press. After entering the university, changes in the living environment, learning environment and other aspect make them gradually have a strong desire for communication, eager to build a harmonious relationship with others. 


\section{The status quo of gratitude psychology of contemporary college students}

\subsection{Lack of awareness}

The strengthening of self-consciousness of contemporary college students causes the differentiation, which often leads to the contradiction between reality and ideals, including emotional problems, employment problems, learning problems and so on. This contradiction tends to be more prominent and leads to some emotional indifference of college students, which then results in slack in their study and life. This kind of slack also includes the decline and loss of awareness of showing gratitude to others.

\subsection{Lack of understanding of the meaning of gratitude}

At this stage, some contemporary college students have a misunderstanding and even certain distorted psychology about the meaning of gratitude. This is one of the main reasons that lead to "cold fish" on campus. The nature of these events fully reflects the contemporary college students' lack of sense of gratitude as well as their coping modes facing frustration. And these events will affect not only students' interpersonal relationship but also the harmonious atmosphere of the campus, and even to a certain extent, threaten the stability and harmony of the society.

\subsection{Lack of effective ability to show their gratitude to others}

College students in China have to face pressure from their study, life, employment and other aspects, which requires them to improve themselves through continuous efforts. The ability to show gratitude to others is very important. However, in reality, college students do not know how to show gratitude to others. Some of them relate gratitude to materials which often leads to embarrassing situation. Some even regard gratitude as a superficial behavior.

\section{Basic principles of carrying out gratitude education for college students from the perspective of positive psychology}

\subsection{Development and prevention}

Positive psychology advocates to cope with the psychological development of college students from the perspective of development and proactively prevent and interfere with it. Different from the traditional teaching model of problem solving, the Gratitude education based on positive psychology emphasizes the development of people's positive psychology to deal with gratitude psychological problems and to promote the overall development of individual students. Therefore, when promoting Gratitude education, educators should always adhere to the principle of combining development and prevention, take preventive measures in advance and always maintain the vision of development to conduct timely intervention for the development of college students' ability to show gratitude to others.

\subsection{Cognition and experience}

Positive psychology focuses on solving problems in real life and exploring the meaning of life from a positive perspective. Therefore, colleges and universities should also follow this principle when conducting Gratitude education, which means to guide students to have a recognition of gratitude in a rational and scientific way as well as understand the nature and connotation of Gratitude education, thus creating experience opportunities and cultivating their positive attitude towards gratitude.

\subsection{Systematic education}

Gratitude education is a complex systematic project which requires the common active participation of schools, society, family and other aspects. The organic combination of teaching system could maximize the advantages of polymerization, and thus gradually build a sound Gratitude education system to create good atmosphere. Teachers, parents and individual students should actively participate in the Gratitude education to complete this systematic teaching task. 


\section{Basic education strategies of carrying out Gratitude education based on positive psychology}

\subsection{Constant optimization of faculty}

Continuous optimization of faculty could guarantee the effective implementation of gratitude education of college students. This means the gratitude education should be organically combined with the ultimate goal of the cultivation of students. Based on the concept of positive psychology, it is necessary to constantly improve the implementation ways of Gratitude education and optimize faculty, aiming to cultivate good psychological quality and personality traits of students. At the same time, emphasizing the teachers' own ability and sense of responsibility is also important. This requires teachers to change their own educational philosophy, have an in-depth understanding of positive psychology, and then conduct more effective guidance for students in the actual Gratitude education.

\subsection{Scientific and rational design of the course of Gratitude education}

Classroom is an important place in education, therefore, the rational and effective use of classroom can also effectively promote the implementation of Gratitude education. According to the concept of positive psychology, the positive role of classroom should be full used. Make a scientific and rational design of the curriculum system of classroom teaching and combine theory and practice to conduct more effective guidance of college students. Moreover, the Gratitude education should also be based on the actual psychological situation of students. Modify and improve the student-centered curriculum and organically combine quality education, ideological and political education with Gratitude education, aiming to carry out a more active training of students' ideology and psychological quality.

\subsection{Use new media to improve Gratitude education}

The broadness and timeliness of the new media provide more effective conditions for the gratitude education of contemporary college students in China. This also requires teachers to fully use the new media in gratitude education and change the traditional teaching in a better way, so that the teaching approach could develop towards a more diversified direction. With the rapid development of Internet in this society, college students have shown great interest in the Internet, therefore, the new media can be used to obtain more information about gratitude education based on positive concept and have an in-depth understanding of the actual situation of college students, thus making Gratitude education more targeted.

\subsection{The integration of the concept of humanistic care into Gratitude education}

Integrating the concept of humanistic care into the training of college students could stimulate the emotional experience of college students, and enable them to participate more actively in the study through emotional guidance. Therefore, the emotional guidance can also be integrated into the Gratitude Education to mobilize the positive thoughts of students under the guidance of positive psychology, so as to help them establish correct values of gratitude. This also requires teachers to pay attention to the differences among individual students and adopt more specific teaching methods, stimulate their positive psychology, thus strengthening their sense of gratitude.

\section{Conclusion}

In the critical period of life development, college students are not psychologically mature yet and face multiple psychological development. College educators should attach great importance to college students' Gratitude education. From the perspective of positive psychology, students should develop good sense of gratitude and master the corresponding practical skills. On this basis, import education and make them constantly adjust themselves, finally learning to show gratitude to others. 


\section{Acknowledgement}

Fund Project: This article is the Higher Education Commission Counselor Project in Shanxi Province in 2017: Research on the Path of Improving the Level of Gratitude under the New Media Environment. Research Results of 2017FKT53

\section{References:}

[1] Emmons R.A.,\& McCullough M.E. The psychology of gratitude. New York: Oxford University Press.2004.

[2] Wang Jiali. On the Life Education of College Students from the Perspective of Positive Psychology [J]. Coal Higher Education .2013 (06)

[3] Chen Xuedi.The path of Thanksgiving Education for college students in the new media environment[J].China Adult Education.2014(21).

[4] Shao Yali. On the Life Education Mode of College Students from the Perspective of Positive Psychology [J]. Journal of Fujian Jiangxia University.2015(01)

[5] Liu Licai..Investigation on gratitude quality of adolescents in China[J].Chinese Youth Studies.2015(01).

[6] Tang Ling.Multidimensional Sruvey on the Study of Gratitude[J].Future and Development.2016(10) 